\title{
Food and Nutrition Systems in India Change as a Result of the Nutrition Transition: The Implications on the Food and Nutrition System in Relating to Changes in the Food Supply and Dietary Intakes
}

\author{
Hilal Salim Al Shamsi ${ }^{1}$, Abdullah Ghthaith Almutairi ${ }^{2}$ \& Sulaiman Salim Al Mashrafi ${ }^{3}$ \\ ${ }^{1}$ Directorate of Planning and Studies, Directorate General of Health Services, Al-Buraimi Governorate, Ministry \\ of Health, Oman \\ ${ }^{2}$ Quality and Patients Safety Department, Prince Nasser bin Saad Hospital, Al-Ghat Province, Ministry of Health, \\ Saudi Arabia \\ ${ }^{3}$ Directorate General of Planning and Studies, Department of Health Information and Statistics, Muscat, Ministry \\ of Health, Oman
}

Correspondence: Hilal Salim Al Shamsi, Directorate of Planning and Studies, Directorate General of Health Services, Al-Buraimi Governorate, Ministry of Health, Oman.

Received: June 8, 2018 Accepted: June 24, 2018 Online Published: August 11, 2018

doi:10.5539/gjhs.v10n9p74 URL: https://doi.org/10.5539/gjhs.v10n9p74

\begin{abstract}
This review examines the implication of changes in nutrition system of India and relates these changes to shifting the dynamics of dietary intakes and food supply. As countries develop economically and socially, the nutrition transition will change the nutrition system. The nutrition transition began to take place in India due to increasing income and urbanization. As the result, there are important issues occurring, increasing the poor diets, obesity, non-communicable diseases, and inactivity.
\end{abstract}

Keywords: nutrition system, India, nutrition transition, transformed, survey, food supply, dietary intakes, demographic transition, urbanization and diet patterns

\section{Introduction}

Since the beginning of human history, major shifts in the food supply and dietary patterns have occurred. Recently, the modification of dietary patterns has accelerated along with socioeconomic and demographic changes in many countries. As countries develop socially and economically, the changing diet is referred to as the nutrition transition (Popkin, 2003). Accordingly, as the income of countries increases, human consumption patterns shift from traditional diets that are high in fibre to ones that are high in sugar, animal products, processed foods and saturated fats. This modification of the food system along with the rising rate of physical inactivity has resulted in an increasing prevalence of overweight and obese individuals as well as non-communicable diseases (NCD) such as diabetes. Moreover, Lim et al., (2012) highlighted that poor nutrition is likely one of the main causes of disability and mortality in the world. Globally, obesity cases have more than doubled since 1980 (World Health Organisation [WHO], 2016). Five patterns have been evidenced in nutrition transition: collecting food, famine, receding famine, degenerative disease (non-communicable disease) and behavioural change (Popkin 2006). These outline the shift from a hunter and gatherer lifestyle to dependence on cereal crops and subsequent famine. Famine then recedes during a secondary agricultural revolution, and more varied diets are adopted. However, changes to the traditional diet and sedentary lifestyles result in health complications, along with resulting behavioural and technological changes to the way food is prepared. Most of the global population today is currently experiencing phases three to five. This paper will assess the impact of changes in nutrition and the food system of India and relate these changes to the shifting dynamics of the food supply and the dietary intake of individuals based on available data and nutritional surveys in the relevant literature. I expect to find that economic and social trends as well as changes in how food is supplied have led to a decreased quality of nutrition in the majority of inhabitants.

Nutritional, demographic and economic transitions have resulted in an epidemic of NCDs in low- and middleincome countries such as India; NCDs have now taken precedence over infectious diseases. Vecchio et al., (2014) highlighted that India has a large diversity of rich diets that are connected to religion, culture and social identity. The nutrition transition began to take place in India due to increasing income and urbanization, leading to the 
consumption of higher quantities of food stemming from more expensive calories such as fruits, vegetables, meats, milk products and fats. This trend is compounded by the increasing rural-to-urban rate of immigration. Yadav and Krishnan (2008) stated that $28 \%$ of the population was living in urban areas in 2001; this population is predicted to reach 618 million by 2025. Furthermore, the life expectancy at birth increased by 27 years in India from 1960 to 2014 (World Bank Group, 2016), and the rate of mortality declined. In addition, the birth rate in India is decreasing (WHO, 2015); this is potentially due to delayed marriage or better access to contraception. Urbanization and lifestyle improvements of lifestyle have resulted from the economic transition. The World Bank Group (2016) pointed out that the gross national income per person (GNI) in 2015 rose 17.7-fold in comparison to 1962. Consequently, food security and literacy has increased, and poverty rates decreased by half from 1970 to 2015 (Planning Commission Government of India 2008). However, this economic transition has driven a rise in sedentary behaviour and a more westernised diet: the main risk factors for obesity and NCDs. Thus, these demographic and economic transitions have also led to a nutrition transition and a higher burden of NCDs in India.

\section{Methods}

The research began in May 2018. Peer-reviewed journal articles and reports in English were consulted from two electronic databases: the Medline nutrition database. In order to restrict the search, the following keywords were used: nutrition system, India, nutrition transition, transformed, survey, food supply, dietary intakes, demographic transition, urbanization and diet patterns. The search process is shown in Figure 1.

Selection Criteria. The selected articles were written in the English language (1), peer-reviewed (2), published during the last 10 years (3), relevant to India (all regions) (4) and contained the study design of surveys and reports on food intake (5).

\section{Results}

This paper considered 22 articles related to the impacts of nutrition transition and changes to the nutrition system, food supply and dietary intakes in India. These references included articles covering the topics of nutrition transition, food supply and dietary changes (14 articles) in addition to articles that solely addressed the food supply (2 articles) or dietary consumption (6 articles).

Using Medline with nutrition from Curtin website, $(\mathrm{n}=1104)$

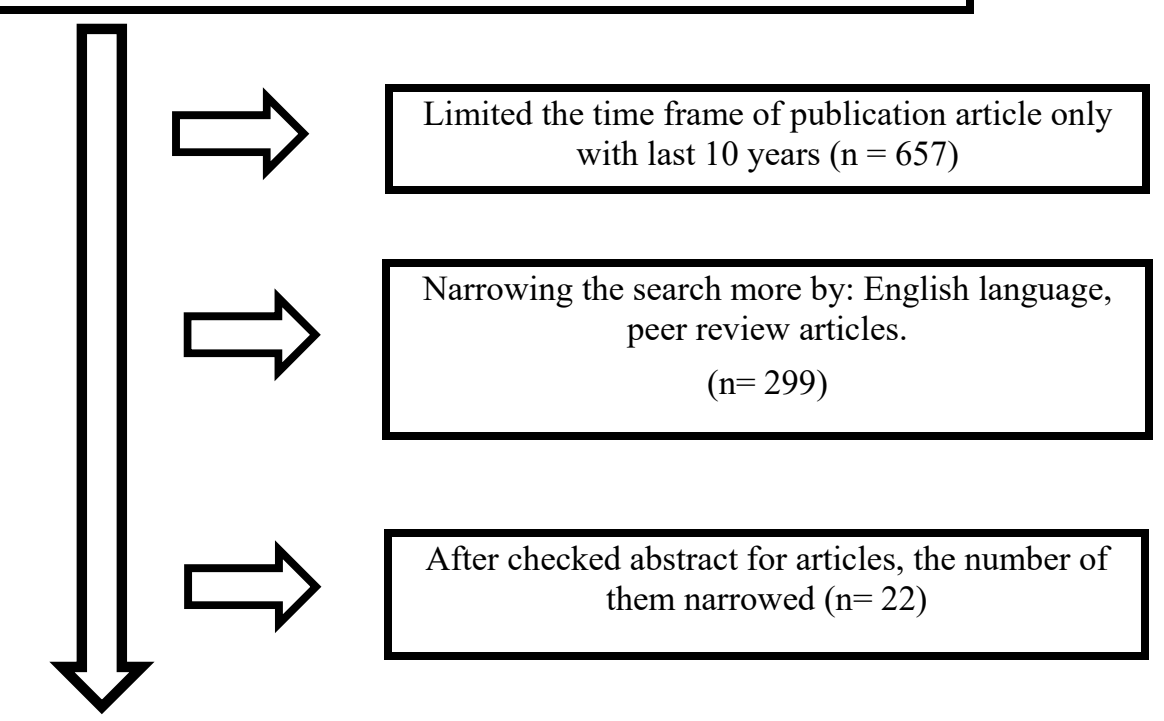

The 22 articles were selected for review. $(\mathrm{n}=22)$

Figure 1. Steps of selection of articles from database

\subsection{Changing Food Supply}

India is beginning to experience changes in the food supply because of increasing urbanisation and foreign 
investment and the need for diet diversification (Pingali and Khwaja 2004). Towns are becoming larger due to rising rates of urbanisation and income. Consequently, large suppliers must manage and provide for these larger markets, resulting in the rise of the fast-food industry and supermarket chains. In addition, Anita \& Singh (2007) pointed out that fast food consumption has increased through advertising in different media such as newspapers, cinema and television. One study in schools of southern India showed that about $98 \%$ of students consumed fast food on a daily basis and $65 \%$ of them had changed their food habits and decision patterns due to media advertising (Anita \& Singh 2007; Joseph et al., 2015). Accordingly, the fast-food industry has increased $40 \%$ yearly over the last decades, including McDonalds, Domino's and Pizza Hut (Anita \& Singh 2007). Singh and Singla (2011) highlighted that poor rural infrastructure and agriculture have led to a shift from agriculture markets to hypermarkets. Moreover, the main Indian cities are located on the coast, so it is easier and cheaper to transform the food supply rather than transport food from the hinterlands (Pingali \& Khwaja, 2004). Thus, urbanization and increasing GNI in India have led to changes in how food is supplied.

These changes to the food supply contribute to the nutrition transition. Landes and Hjort (2015) stated that previously, the food demand in India depended on agriculture. The supply of food products such as edible oils, fruit, meats, dairy products and vegetables was robust (Landes \& Hjort, 2015). Agriculture once formed the main resource for healthy diets, whereas currently, the food supply is centred on providing a variety of cheap and tasty foods with a long shelf-life (Anita \& Singh, 2007). However, this has resulted in a dietary shift; calories once obtained from cereals now come from more expensive sources such as milk, oils and meats (Anita \& Singh, 2007; Deaton \& Drèze, 2009). Fast foods such as sandwiches, pizzas and burgers are quick, cheap and now readily available (Anita \& Singh, 2007). These meals have a high content of sugar, salt, saturated fat, carbohydrates and calories (Adams, 2005; Anita \& Singh, 2007). Hypermarkets and supermarkets now supply a variety of high quality foods such as milk, meat, vegetables and oil. Furthermore, Gill et al., (2015) outlined how the supply of vegetable oil is associated with the nutrition transition in India. In brief, the supply of a variety of foods has rapidly increased in India and may be related to the nutrition transition.

\subsection{Trends in Dietary Consumption}

Several studied have outlined the specific changes in diet. Males were found to consume more vegetables and fruits than females (Yadav \& Krishnan 2008; Sébastia, Balagopal, \& Misra, 2013); (Singh et al., 2015; Vaz et al., 2005). Yadav and Krishnan (2008) stated that the weekly consumption of fruits and vegetables represents $6.3 \%$, $7.7 \%$ and $8.1 \%$ of the diet of males from urban areas, rural areas and urban slums, respectively. Another study shows that more than $85 \%$ of Indian females consume fruit and vegetables at least once a week (Padmadas, Dias, \& Willekens, 2006). However, the daily consumption of fruit and vegetables is $25 \%$ below the recommended 2 servings of fruit and 5 servings of vegetables in India.

Economic, marketing and infrastructure improvements in addition to social changes have led to an increased consumption of milk and milk products, fats, sugar, salt and other animal products (Kapil \& Sachdev, 2012). Popkin (2014) highlighted that as income decreases, the consumption of vegetable oils increases, while the consumption of healthy foods such as fruit, vegetables, legumes, fibre and coarse grains decreases. An additional study highlighted that sugar intake has decreased in urban areas and increased in rural areas (Aurino, Fernandes and Penny 2016). Overall, dietary intake has shifted toward high consumption of carbohydrates, proteins and fats.

Carbohydrates. Energy consumption from carbohydrates is high in India (Misra and Vikram 2004; Misra et al., 2011). Pingali and Khwaja (2004) indicated that cereals such as wheat and rice are the main source of carbohydrates. Moreover, consumption of carbohydrates from cereals has decreased in both rural and urban areas in the last two decades (National Sample Survey Organization -India (NSSO) 2006). Declining cereal intake may be caused by increasing fast food consumption (Anita \& Singh, 2007; Sébastia, Balagopal, \& Misra, 2013). A decline in cereal consumption has been linked to the increasing prevalence of NCDs such as type 2 diabetes mellitus and obesity in India (Misra et al., 2011).

Protein. During the last three decades, a shift in protein consumption has also occurred from vegetable to animal sources, whether meat or milk (Singh et al., 2015; Kapil \& Sachdev, 2012). Aurino, Fernandes, and Penny (2016) highlighted that the main dietary sources of protein in India are nuts, meat, fish, eggs, milk and dairy products. The consumption of protein in India was estimated to be $57 \mathrm{grams} /$ person/day, contributing to $11 \%$ of dietary energy (NSSO 2006). Modifications to the food supply and the abundance of fast food and hypermarkets may be the main causes of this shift from vegetable to animal protein (Aurino, Fernandes, \& Penny, 2016).

Fat. Previously, the Indian diet mostly depended on vegetarian and plant sources with invisible fat. Recently, dietary patterns have increasingly depended on animal products such as butter, ghee and vegetable oil (Misra et al., 2011; Misra, Singhal, \& Khurana, 2010). Fat intake increased in both rural and urban areas by 7\% from 1980 to 2005 (Food and Agriculture Organization of the United Nations [FAO] 2004). Currently, the energy obtained 
from fats in urban and rural populations increased to $16 \%$ and 21\%, respectively (Misra et al., 2011). Furthermore, unhealthy oils and fats have become key ingredients in nearly every prepared Indian dish, as outlined by Popkin (2014).

\subsection{Physical Activity}

Overall, physical activity shows a decreasing trend, although one study shows that rural men have four times more physical activity than urban men (Yadav and Krishnan 2008). This study also highlights that urban men had more physical inactivity in transport (37.7\%) and work (92.4\%) compared to urban slums and rural areas. Vaz et al., (2005) indicated that $51 \%$ of females and $61 \%$ of males in India have sedentary lifestyles.

\subsection{The Rate of Obesity and NCDs in India}

Although the prevalence of undernutrition in children under 5 years of age decreased by $23 \%$ between 1975 and 2012 (National Nutrition Monitoring Bureau of India [NNMB] 2012), between 2000 and 2005 the rate of obesity increased $0.4 \%$ yearly in men and $0.5 \%$ yearly in women (NNMB, 2006). In addition, the rate of NCDs increased rapidly in the last decade in India. The prevalence of NCDs in Mumbai city increased from 3\% of the population in 1959 to 44\% in 1999 (Vaz et al., 2005). Furthermore, Mohan et al., (2007) stated that the prevalence of diabetes was 40 million in 2006 and is expected to reach about 70 million by 2025 .

\section{Discussion}

The nutrition transition is a result of demographic and socioeconomic changes in India. Misra et al., (2011) stated that the nutrition transition has occurred in three stages in India. First, consumers shifted from traditional diets to westernised diets. Second, the impact of globalization has led to an increased number of markets, and consumers have greater access to a wider variety of processed and ready-to-eat foods. Third, consumers changed their eating habits and adapted to new food products. Thus, the changing food supply has likely altered dietary patterns.

\subsection{Food Supply}

In recent decades, the food supply in India has shifted from a traditional, local supply to one that is global. The change in the food supply is a result of urbanization, increasing GNI, increasing population and changes in the social environment (Anita \& Singh, 2007; Pingali \& Khwaja, 2004).

Several factors may influence consumers to change their food habits and consume more fast food such as home environment, accessibility, availability and also media advertising. Bowman (2005) stated that consumers who eat fast-food meals consume more calories, fats, carbohydrates, proteins and sugars and less fibre, fruit, vegetables and milk than those who do not. Therefore, the fast-food industry can result in a shift in dietary patterns from a healthy, traditional diet to an unhealthy diet that is high in calories, saturated fat, salt, sugar and carbohydrate. In brief, the rapid distribution of fast food throughout India has contributed to shifting dietary patterns.

Supermarkets have also expanded and are able to provide a wide variety of products of both high quality and quantity. Pingali and Khwaja (2004) stated that supermarkets provide a wide range of products, from fresh products to household electrical devices and detergents, thus enabling the consumer to avoid visiting several retail outlets. Consequently, local farmers have been affected, and there are fewer consumers for domestic or local markets or retail outlets; supermarkets are largely not supplied with local agricultural products. Reardon and Minten (2011) highlighted that supermarkets are needed in India due to poor agriculture and infrastructure, as this raises the cost of transporting and storing fresh food. As part of this trend, agricultural lands reduced from $61.1 \%$ of the total land area in 1991 to $60.4 \%$ in 2012 (The World Bank 2016). Thus, the expansion of supermarkets has affected local agriculture in India.

Thus, the changing food supply has influenced health and nutrition in India. The previous food supply system depended on local products from agriculture, fisheries and livestock, representing healthy nutrition sources, whereas globalization changed the dynamics of the food supply, providing a wide variety of processed food products (Anita \& Singh 2007). Many of these food products have a high salt, sugar, saturated fat, carbohydrate and calorie content (Adams 2005; Anita \& Singh 2007). Moreover, the globalization of food has increased prices by $10 \%$ since 2010 (Asian Development Bank 2011). A quarter of the population in India is living in poverty, so increasing food prices can affect access to quality nutrition for impoverished persons. In brief, the food supply has shifted to processed food products and also resulted in increased food prices.

\subsection{Trends in Dietary Consumption}

The nutrition transition may be framed as a result of urbanization and increasing income and food diversity. Traditional eating habits have been lost as people begin to adapt to a new dietary pattern in India. Kapil and Sachdev (2012) highlighted the rising consumption of fats, sugar, salt, milk, milk products and other animal products. Meanwhile, the consumption of healthy foods such as high-fibre vegetables, fruit, legumes and coarse 
grains decreased (Popkin, 2014). Thus, the nutrition transition has resulted in a shift toward an unhealthier and cheaper diet, especially for low-income consumers.

In the past, Indians derived a large portion of their carbohydrates from whole grains. In recent decades, many of these have been replaced with refined carbohydrates from cereals such as white rice and wheat (Pingali \& Khwaja, 2004). Hu (2010); (Hu 2011) highlighted that refined carbohydrate consumption increases levels of insulin and plasma glucose in the human body, leading to insulin resistance. Corresponding trends appear to support this shift. For example, rice yields have increased since 1991 and have begun to replace coarse grains. The consumption of coarse grains per capita decreased in both urban and rural areas by 24.46 kilograms $(\mathrm{kg})$ and $9.73 \mathrm{~kg}$, respectively, from 1987 to 2010 (National Council of Applied Economic Research/New Delhi [NCAER], 2014). Thus, the nutrition transition has also involved a shift in the type of carbohydrates in the diet.

In addition, the nutrition transition in India has impacted the intake of proteins and fats. First, cereals and vegetables were once major protein sources, whereas in the current food supply protein sources often stem from animal products, whether meat or milk (Anita \& Singh, 2007; Kapil \& Sachdev, 2012). One study indicated that consumption of protein from eggs/fish/meat and milk increased by $26 \%$ and $24 \%$, respectively, while protein from cereals decreased by 7\% from 1987 to 2010 (NCAER, 2014). Second, Indians shifted from consuming invisible fat in plant food to visible fat in animal products. Fat intake increased by 7\% in India from 1980 to 2005 (FAO, 2004). Accordingly, the diet has shifted from one that is high in monounsaturated fat, present in olives, nuts and seeds, to a diet that is high in saturated and trans fats, present in fatty meats, dairy products, vegetable oil, snacks food and fast food (Arora et al., 2014). Currently, India imports about 18 million metric tons of vegetable oil yearly (Directorate General of Commercial Intelligence and Statistics - India, 2016). This may be one contributing factor toward the increasing incidence NCDs and obesity in India.

Furthermore, it is notable that physical activity has decreased along with shifting dietary patterns. The means of transport, devices in the home, market production and reduction of manual tasks in the workplace have contributed to a more sedentary lifestyle. A cross-sectional study in India showed that $65 \%$ of urban dwellers were physically inactive in addition to $50 \%$ of rural people (Anjana et al., 2014). Both the nutrition transition and levels of physical activity could have negative impacts on the health status of Indians. Moreover, the prevalence of NCDs has increased rapidly in recent decades in India. For example, the number of persons affected by diabetes increased by 8.9 million from 2000 to 2006 . Thus, the nutrition transition appears to be having negative impacts on the health of Indians. The main limitation of this paper was the eventual use of reports published before 2006 since these were the most available and thus served as the main sources.

\section{Conclusions}

The nutrition transition has impacted the food and nutrition system in India. Rapid rises in population, GNI, globalization and urbanization have led to shifts in Indian food supply and diet patterns. The food supply was previously dependent on agriculture, livestock and fishing, but has currently transitioned toward a greater availability of processed, tasty products with a long shelf-life. The fast-food industry and the supermarkets provide a wide range of products that are high in calories, refined carbohydrate, protein and saturated fat. Moreover, fast food in India expands yearly at a rate of $40 \%$. Consequently, domestic markets and agriculture have been affected by the growing supermarket and fast food industries. Specifically, the consumption of healthy carbohydrates, proteins from cereals and monounsaturated fats has shifted toward the consumption of refined carbohydrates, animal proteins and saturated fats. Physical inactivity also rose in both urban and rural areas of India due to urbanization, globalisation of the food supply and new technologies. Although the prevalence of undernutrition has decreased, the prevalence of overweight and obese individuals as well as NCDs such as hypertension and diabetes have increased. Therefore, the nutrition transition may negatively affect the health of the Indian population. In light of the expanding supermarket and fast food industries, more support is needed for farmers; this may be achieved by purchasing directly from farmers. Moreover, interventions are required in order to increase the awareness of consumes of unhealthy diet patterns. Further research on food supply and policy in India is required.

\section{Competing Interests Statement}

The authors declare that there are no competing or potential conflicts of interest.

\section{References}

Adams, R. (2005). Fast food, obesity, and tort reform: an examination of industry responsibility for public health. Business and Society Review, 110(3), 297-320. https://doi.org/10.1111/j.0045-3609.2005.00017.x.

Goyal, A., \& Singh, N. P. (2007). Consumer perception about fast food in India: an exploratory study. British Food Journal, 109(2), 182-195. https://doi.org/10.1108/00070700710725536. 
Anjana, R. M., Pradeepa, R., Das, A. K., Deepa, M., Bhansali, A., Joshi, S. R., ... \& Subashini, R. (2014). Physical activity and inactivity patterns in India-results from the ICMR-INDIAB study (Phase-1)[ICMR-INDIAB-5]. International Journal of Behavioral Nutrition and Physical Activity, 11(1), 26. https://doi.org/10.1186/14795868-11-26.

Arora, N. K., Pillai, R., Dasgupta, R., \& Garg, P. R. (2014). Whole-of-society monitoring framework for sugar, salt, and fat consumption and noncommunicable diseases in India. Annals of the New York Academy of Sciences, 1331(1), 157-173. https://doi.org/10.1111/nyas.12555.

Asian Development Bank. (2011. Global Food Price Inflation and Developing Asia/Asian Development Bank. Edited by Bank Asian Development. Manila: Manila: Asian Development Bank.

Aurino, E., Fernandes, M., \& Penny, M. E. (2017). The nutrition transition and adolescents' diets in low-and middle-income countries: a cross-cohort comparison. Public health nutrition, 20(1), 72-81. https://doi.org/10.1017/S1368980016001865.

Bowman, S. A. (2005). Agricultural research. Science Update, 53(1), 23. Retrieve from http://www.springer.com/life+sciences/cell+biology/journal/40003

Deaton, A., \& Drèze, J. (2009). Food and nutrition in India: facts and interpretations. Economic and political weekly, 42-65. http://www.jstor.org.dbgw.lis.curtin.edu.au/stable/40278509? seq=1\#page_scan_tab_contents.

Directorate General of Commercial Intelligence and Statistics-India. (2016). Publications of Dgci\&S.

Food and Agriculture Organization of the United Nations [FAO]. (2004). Food and Nutrition Paper 83: Globalization of Food Systems in Developing Countries: Impact on Food Security and Nutrition.

Gill, M., Feliciano, D., Macdiarmid, J., \& Smith, P. (2015). The environmental impact of nutrition transition in three case study countries. Food Security, 7(3), 493-504.https://doi.org/10.1007/s12571-015-0453-x.

Hu, F. B. (2010. Are Refined Carbohydrates Worse Than Saturated Fat? The American journal of clinical nutrition 91 (6): 1541. https://doi.org/10.3945/ajcn.2010.29622.

. (2011). Globalization of Diabetes: The Role of Diet, Lifestyle, and Genes. Diabetes care 34 (6): 1249. https://doi.org/10.2337/dc11-0442.

Joseph, N., Nelliyanil, M., Rai, S., YP, R. B., Kotian, S. M., Ghosh, T., \& Singh, M. (2015). Fast food consumption pattern and its association with overweight among high school boys in Mangalore city of southern India. Journal of clinical and diagnostic research: JCDR, 9(5), LC13. https://doi.org/10.7860/JCDR/2015/13103.5969.

Landes, M., \& Hjort, K. (2015). Food Policy and Productivity Key to India Outlook. Amber Waves, (06), 5-15. Retrieved from http://search.proquest.com.dbgw.lis.curtin.edu.au/docview/1701618357?rfr_id= info\%3Axri\%2Fsid\%3Aprimo.

Misra, A., Singhal, N., \& Khurana, L. (2010). Obesity, the metabolic syndrome, and type 2 diabetes in developing countries: role of dietary fats and oils. Journal of the American College of Nutrition, 29(sup3), 289S-301S. https://doi.org/10.1080/07315724.2010.10719844.

Misra, A., Singhal, N., Sivakumar, B., Bhagat, N., Jaiswal, A., \& Khurana, L. (2011). Nutrition transition in India: Secular trends in dietary intake and their relationship to diet-related non-communicable diseases. Journal of diabetes, 3(4), 278-292. https://doi.org/10.1111/j.1753-0407.2011.00139.x.

Misra, A., \& Vikram, N. K. (2004). Insulin resistance syndrome (metabolic syndrome) and obesity in Asian Indians: evidence and implications. Nutrition, 20(5), 482-491. https://doi.org/10.1016/j.nut.2004.01.020.

Mohan, V., Sandeep, S., Deepa, R., Shah, B., \& Varghese, C. (2007). Epidemiology of type 2 diabetes: Indian scenario. The Indian journal of medical research, 125(3), 217-30. Retrieved from http://icmr.nic.in/ijmr/2012/october/Most_cited2.pdf.

National Council of Applied Economic Research/New Delhi [NCAER]. (2014). An Analysis of Changing Food Consumption Pattern in India. Retrieved from http://nfsm.gov.in/

National Nutrition Monitoring Bureau of India [NNMB]. (2006). Diet and Nutritional Status Pf Population and Prevalence of Hypertension among Adults in Rural Areas.

National Nutrition Monitoring Bureau of India [NNMB]. (2012). Diet and Nutritional Status of Rural Population, Prevalence of Hypertension \& Diabetes among Adults and Infant \& Young Child Feeding Practices.

National Sample Survey Organization-India [NSSO]. (2006). Level and Pattern of Consumer Expenditure, 2004- 
05. Retrieved from http://mospi.nic.in/rept\%20_\%20pubn/508_final.pdf

Padmadas, S. S., José, G. D., \& Frans, J. W. (2006). Disentangling Women's Responses on Complex Dietary Intake Patterns from an Indian Cross-Sectional Survey: A Latent Class Analysis. Public Health Nutr., 9(2), 204-211. https://doi.org/10.1079/PHN2005842.

Pingali, P., \& Khwaja, Y. (2004). Globalisation of Indian diets and the transformation of food supply systems. Indian Journal of Agricultural Marketing, 18(1), 2004.

Planning Commission Government of India. (2008). Eleventh Five Year Plan: 2007-12.

Popkin, B. M. (2003. The Nutrition Transition in the Developing World. Development Policy Review, 21(5-6), 581597. https://doi.org/10.1111/j.1467-8659.2003.00225.x.

- (2006). Global Nutrition Dynamics: The World Is Shifting Rapidly toward a Diet Linked with Noncommunicable Diseases. Global nutrition dynamics: the world is shifting rapidly toward a diet linked with noncommunicable diseases, 84(2), 289-298. Retrieved from http://ajen.nutrition.org.dbgw.lis.curtin.edu.au/content/84/2/289

- (2014). Synthesis and Implications: C Hina's Nutrition Transition in the Context of Changes across Other Low- and Middle-Income Countries.

Reardon, T., \& Minten, B. (2011). The quiet revolution in India's food supply chains. IDEAS Working Paper Series from RePEc. Retrieved from http://search.proquest.com.dbgw.lis.curtin.edu.au/docview/1698100235?rfr_id=info\%3Axri\%2Fsid\%3Apri mo

Sébastia, B.e, Padmini, B., \& Ranjita, M. (2013). Diet-Related Diseases: Issues and Solutions to Nutrition Transition and Food Programme Policies in India. Retrieved from https://www.researchgate.net/publication/236143159_Diet-

related_diseases_Issues_and_solutions_to_nutrition_transition_and_food_programme_policies_in_India.

Singh, A., Gupta, V., Ghosh, A., Lock, K., \& Ghosh-Jerath, S. (2015). Quantitative estimates of dietary intake with special emphasis on snacking pattern and nutritional status of free living adults in urban slums of Delhi: impact of nutrition transition. BMC nutrition, 1(1), 22. https://doi.org/10.1186/s40795-015-0018-6.

Singh, S., \& Singla, N. (2011). Fresh food supermarkets in India: An analysis of their inclusiveness and impact on primary producers. Millennial Asia, 2(1), 65-91. https://doi.org/10.1177/097639961100200105.

The World Bank. (2016). Agricultural Land (\% of Land Area).

Kapil, U., \& Sachdev, H. P. S. (2012). Urgent need to orient public health response to rapid nutrition transition. Indian journal of community medicine: official publication of Indian Association of Preventive \& Social Medicine, 37(4), 207. https://doi.org/10.4103/0970-0218.103465.

Vaz, M., Yusuf, S., Bharathi, A. V., Kurpad, A. V., \& Swaminathan, S. (2005). The nutrition transition in India. South African Journal of Clinical Nutrition, 18(2), 198-201. http://reference.sabinet.co.za/webx/access/electronic_journals/m_sajen/m_sajcn_v18_n2_a28.pdf.

Vecchio, M. G., Paramesh, E. C., Paramesh, H., Loganes, C., Ballali, S., Gafare, C. E., ... \& Gulati, A. (2014). Types of food and nutrient intake in India: a literature review. The Indian Journal of Pediatrics, 81(1), 17-22.

World Bank Group. (2016). Data for South Asia, India.

World Health Organisation [WHO]. (2015). Preterm Birth. . (2016). Obesity and Overweight.

Yadav, K., \& Krishnan, A. (2008). Changing patterns of diet, physical activity and obesity among urban, rural and slum populations in north India. Obesity reviews, 9(5), 400-408. https://doi.org/10.1111/j.1467789X.2008.00505.x.

\section{Copyrights}

Copyright for this article is retained by the author(s), with first publication rights granted to the journal.

This is an open-access article distributed under the terms and conditions of the Creative Commons Attribution license (http://creativecommons.org/licenses/by/4.0/). 